expression levels and DMR methylation states varied greatly in all nine ES cell lines tested. Similar variation was observed even between subclones from a single ES cell line. These observations indicate that the epigenetic changes occur while ES cells are cultured, supporting previous suggestions that their epigenetic states are very unstable - so unstable that expression levels vary even between animals derived from the same ES cell subclones. Contrary to previous beliefs, mammalian development must be relatively robust because cloned embryos can survive despite such variation in gene expression.

It remains to be seen if human ES cells have similarly variable gene expression. If so, their clinical applications might be more limited than previously expected.

Magdalena Skipper

(2) References and links ORIGINAL RESEARCH PAPER Humpherys, D. et al. Epigenetic instability in ES cells and cloned mice. Science 293, 95-97 (2001) WEB SITE Rudolf Jaenisch's lab

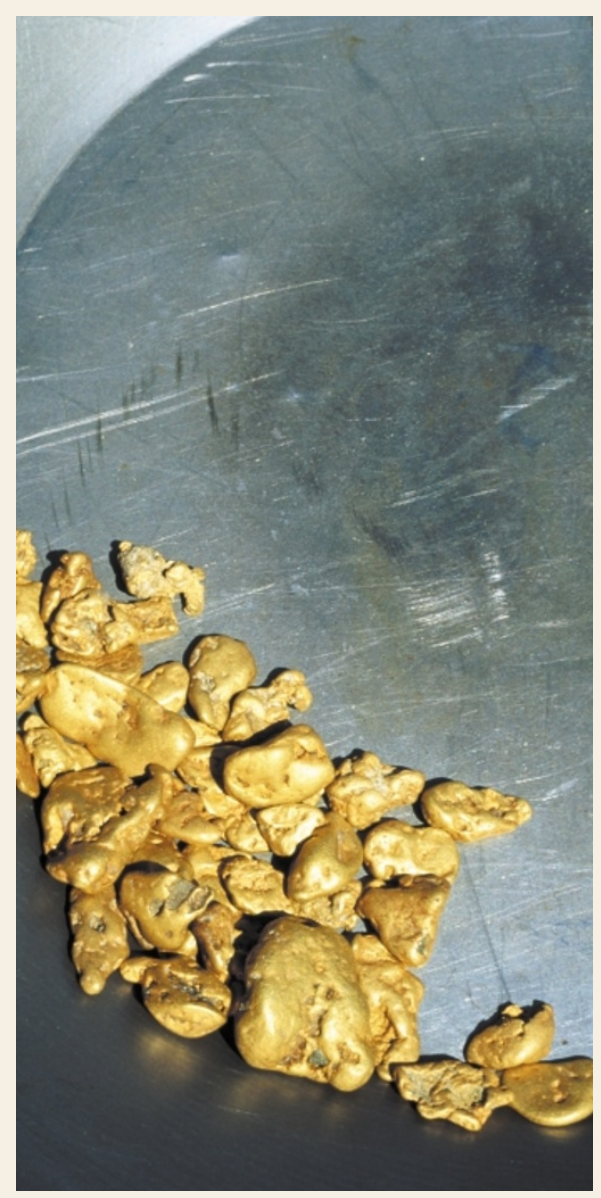

TECHNOLOGY

\section{A better mouse trap}

Loss-of-function mutants are available for only a small fraction of mouse genes, but this shortage is being addressed by several strategies, such as chemical mutagenesis, gene targeting and gene trapping. Insertion vectors are used as mutagens in gene trapping, which therefore has the advantage that mutated genes can be cloned rapidly from any mutant strain of interest. However, there has been some concern that gene trapping might lead to loss-offunction mutations only infrequently and that it is not efficient enough for large-scale projects. A recent paper by Bill Skarnes and colleagues seems to lay these concerns to rest.

Gene-trapping vectors contain reporter genes that are only expressed if the vector integrates within an expressed gene.

Transfected mouse ES cells that express the reporter gene are therefore likely to carry a gene interrupted by the vector, and the phenotypic consequences of this can then be studied in mouse embryos. The vector used by Mitchell et $a l$. was designed to express the reporter genes only if the vector was inserted into a gene that expresses a signal sequence or transmembrane domain. They reasoned that secreted or membrane-spanning proteins are likely to be involved in important developmental processes, such as signalling and cell adhesion, and that their disruption will cause a range of developmental phenotypes.

Over 500 ES cell lines that express the reporter genes were studied and most contained insertions in genes known, or predicted, to encode secreted or transmembrane proteins. From these lines, 60 were used to create mouse embryos, of which 25 had a clearly abnormal phenotype. The phenotypes ranged from early defects in processes such as gastrulation and implantation to abnormalities in later developing structures, such as the limb and eye. Furthermore, 11 of these mutants could be compared with existing gene knockouts, and in 10 cases the null phenotype was identical to that of the gene-trap mutant. This indicates that the secretory gene-trapping method efficiently generates loss-of-function mutations, and can be used in both gene-based and phenotypedriven screens. The authors argue that a closer analysis of the 35 lines that do not have overt abnormalities is also likely to uncover further

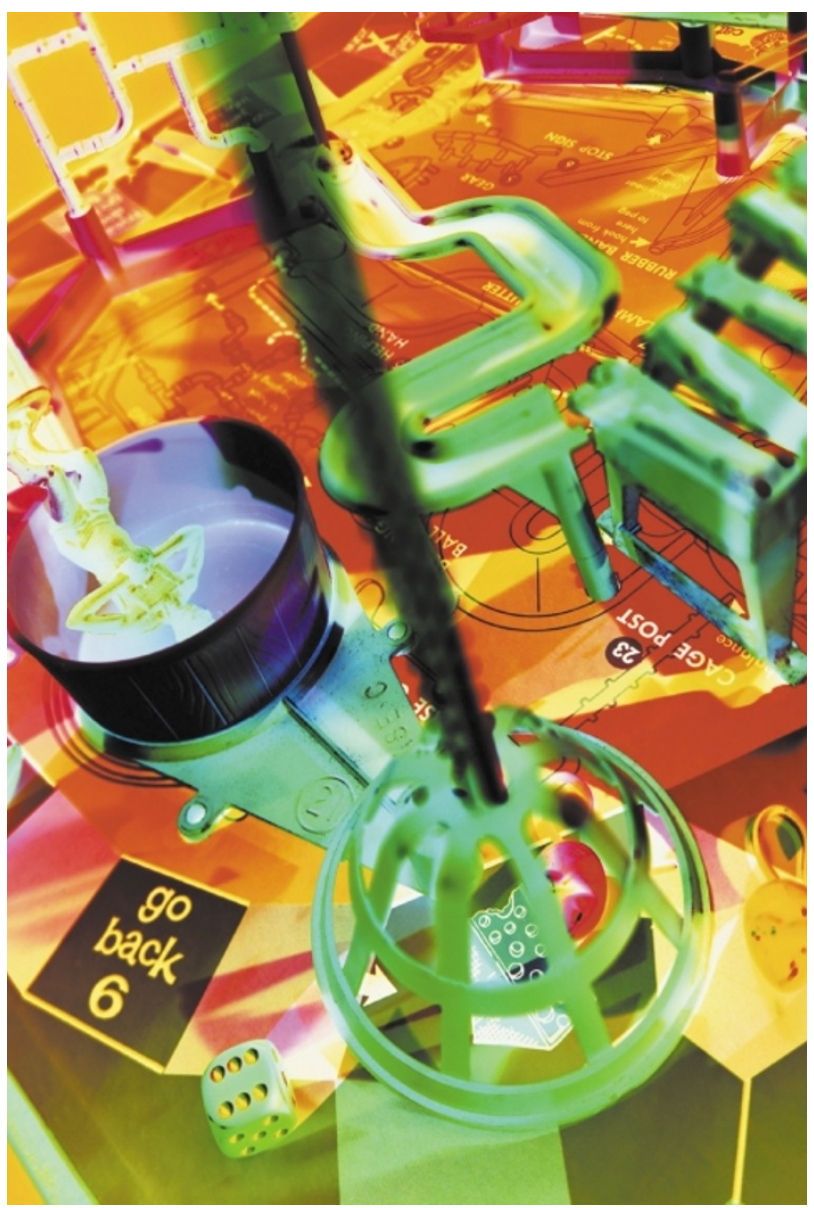

phenotypes. Indeed, a concurrent screen using a cell-autonomous axonal marker in the genetrap vector has revealed axon guidance defects in two of these lines.

Overall, Mitchell et al. can assign new functions to nine known, and five new, genes. In an accompanying News and Views, Ian Jackson likens those who argue about whether forward or reverse genetics is better for functional analysis of mouse genes to the Lilliputians and Blefuscans in Gulliver's Travels, who fought over which end of a boiled egg should be eaten first. By combining aspects of forward genetic screens and knockout technology, gene trappers might be said to be tackling the egg from somewhere in the middle. However, in this case the competition seems to be healthy and the technology for studying gene function is advancing on all fronts.

Mark Patterson

\section{(2) References and links}

ORIGINAL RESEARCH PAPER Mitchell, K. et al. Functional analysis of secreted and transmembrane proteins critical for mouse development. Nature Genet. 28, 241-249 (2001)

FURTHER READING Jackson, I. Mouse mutagenesis on target. Nature Genet. 28, 198-200 (2001) | Leighton, P. A. et al. Defining brain wiring patterns and mechanisms through gene trapping in mice. Nature 410, 174-179 (2001)

WEB SITE Bill Skarnes' lab 